\title{
IGLESIA E INQUISICIÓN EN CARTAGENA DE INDIAS DURANTE EL TRÁNSITO DE LA ÉPOCA COLONIAL A LA INDEPENDENCIA*
}

\author{
JuAn Jesús Bravo CARo \\ Universidad de Málaga
}

Fecha de recepción: diciembre 2013

Fecha de aceptación: mayo 2014

\section{INTRODUCCIÓN}

Grandes obras han tratado el tema de la implantación y desarrollo de la Inquisición en América. Cartagena de Indias, Chile, Lima y México cuentan con importantes estudios que tienen siempre el punto de referencia en los libros de José Toribio Medina ${ }^{1}$. Sin embargo, el tribunal cartagenero todavía debe ser más investigado.

Las propuestas de creación de nuevos distritos son constantes desde la misma instauración de los de Nueva España y el Perú. Incluso, algunos memoriales elevados a las autoridades competentes en esta materia siguen reclamando su erección en fechas tan tardías como la de $1816^{2}$.

Nos interesa la Inquisición en el contexto de los cambios políticos experimentados en el tránsito del siglo XVIII al XIX, y los conflictos con otras instituciones, caso de la Iglesia y los poderes civiles emergentes, en lo que se refiere al control de las dis-

\footnotetext{
* Trabajo inserto en el marco del Proyecto de Investigación HUM2006-12653-C04-03, financiado por el Ministerio de Educación y Ciencia de España.

1. Medina, José Toribio: Historia del Tribunal del Santo Oficio de la Inquisición de Lima (1569-1820), Santiago de Chile, 1887 (Existe una versión editada en Santa Fe, El Cid Editor, 2004); Historia del Tribunal del Santo Oficio de la Inquisición en Chile, Santiago de Chile, 1890, (Existe una versión editada en Santa Fe: El Cid Editor, 2004); Historia del Tribunal del Santo Oficio de la Inquisición de Cartagena de Indias, Santiago de Chile, 1899; Historia del Tribunal del Santo Oficio de la Inquisición en México, Santiago de Chile, 1905 (Existe una 1a edición de la obra, con prólogo de Solange Alberro: México: Consejo Nacional de la Cultura y las Artes, 1991. 2a edición en México: Miguel Ángel Porrúa, 1998).

2. Archivo General de Indias de Sevilla (A.G.I.), Indiferente, leg. 3014B.
} 
tintas formas de disidencia. La teórica uniformidad eclesiástica perseguida por el Real Patronato de Indias mostró divergencias, que desembocaron en modelos diferentes a la hora de establecer las relaciones Estado-Roma a partir de 1810.

El objetivo de este trabajo es examinar las actuaciones en el distrito de Cartagena de Indias y comparar comportamientos similares en los de Lima y México, desde el ámbito de los conflictos de competencia, represión de la masonería, prevención de ideas presuntamente subversivas, y la represión de las conexiones con los movimientos de independencia.

\section{EL MARCO DEL REAL PATRONATO HASTA LA INDEPENDENCIA}

El 28 de julio de 1508, la bula Universalis Ecclesiae Regiminis concedía a los monarcas españoles el Patronato Universal de todas las iglesias en las Indias ${ }^{3}$. Tal concesión iba a promover un gran número de obras durante el periodo colonial y los años inmediatos al fenómeno independentista latinoamericano, al objeto de justificar las diversas interpretaciones operadas por los poderes regios y eclesiásticos ${ }^{4}$. La extensión a los territorios incorporados a la Monarquía Hispánica desde 1492 los dejaría bajo los parámetros diseñados a finales del siglo XV, en el marco del Regio Patronato concedido a los Reyes Católicos, a aplicar al reino de Granada, recién conquistado, y a las Islas Canarias 5 . Pero pese a ser una concesión de Roma, no estuvo exenta de conflictividad, pues de lo que se trataba en última instancia era del propio ejercicio del poder del Estado emergente frente a una prerrogativa papal, que había tenido delegaciones concretas durante la baja Edad Media, sin la dimensión alcanzada con la irrupción de las monarquías nacionales. Como es lógico, el ámbito americano conocería un debate muy interesante en esta materia a lo largo de la Edad Moderna ${ }^{6}$, quedando vestigio en la legislación promulgada ${ }^{7}$.

Unos sesenta años después de la concesión papal reseñada otra decisión de no menor trascendencia iba mostrar la preocupación de la Corona por ejercer un control decidido sobre los nuevos territorios en Indias. El establecimiento del Tribunal del Santo Oficio, a partir de 1570, en los distritos que serían erigidos después del limeño, perseguía ejercer una vigilancia de sus súbditos, pero sobre todo del componente conquistador-colonizador asentado por toda la geografía central y meridional de América. Lima, México, Cartagena de Indias y Chile asumieron las sedes de la tan temida institución, cuya evolución estuvo sometida a las mismas coyunturas de los

3. De Leturia, Pedro: Relaciones entre la Santa Sede e Hispanoamérica: 1493-1835. 1. Época del Real Patronato, 1493-1800, Roma, 1959, pp. 253-258.

4. Hermann, Christian: L'eglise d'Espagne sous le Patronage royal (1476-1834). Essai d'ecclésiologie politique, Madrid, 1988, pp. 111-128.

5. Garrido Aranda, Antonio: Organización de la Iglesia en el reino de Granada y su proyección en Indias. Siglo XVI, Sevilla, 1980, pp. 141-248.

6. SÁnchez Bella, Ismael: Iglesia y Estado en la América española, Pamplona, 1991, pp. 55-106.

7. Recopilación de Leyes de los Reynos de las Indias, Madrid, 1681. 
cerca de doscientos cincuenta años de su existencia: del esplendor internacional de la Monarquía española como potencia europea y colonial, hasta la pérdida final de ese papel relevante junto al inicio de la época independentista de principios del siglo XIX.

Al fin y al cabo, tanto en la metrópoli como en Indias, el Real Patronato no consiguió la paz interior en el seno de la Iglesia. El Tribunal de la Inquisición, creado también con unos fines muy concretos, manifestó múltiples disputas con los cabildos catedrales $^{8}$, obispos y clero en general, a una y otra orilla del Atlántico, aunque determinados autores son de una opinión difícil de sostener, al afirmar que existieron escasas discrepancias y «fútiles»». La política regalista de los Borbones no hizo si no potenciar la mediación, como mínimo, en los litigios producidos en el ámbito contemplado del Real Patronato, en defensa de los derechos y regalías obtenidas por la Corona ${ }^{10}$. Estas desavenencias no pasaron desapercibidas para la prensa del momento, y aprovecharon las disputas inter-institucionales para resaltar lo pernicioso de mantener el poder del clero y de todo lo que suponía, alentando decididamente la intervención sobre los bienes del mismo con especial atención a lo concerniente a las cofradías ${ }^{11} \mathrm{y}$ a la Inquisición ${ }^{12}$. En este sentido las propiedades de los tribunales inquisitoriales, y de aquellas hermandades dependientes de ellos por la geografía americana, serían intervenidas ${ }^{13}$. El Santo Oficio representaba todas las características perniciosas de la Iglesia.

La cuestión del Patronato Indiano se vio también inmersa en los cambios operados durante las primeras décadas del siglo XIX. Evidentemente, la problemática generada a raíz del establecimiento de la primacía de la Monarquía española sobre los asuntos eclesiásticos, en principio en materia de presentación al Papa de los candidatos más adecuados a los principales puestos de la Iglesia, en la metrópoli o en los territorios americanos, sufriría críticas acordes con el tiempo vivido. Pero las reformas de los Borbones, y el impulso nítido de un regalismo lo más amplio posible, no obtuvo la modificación de las competencias de la Monarquía respecto a lo existente antes de 1700 sobre la Iglesia en Indias ${ }^{14}$. La supeditación del episcopado y de la Iglesia a la Corona, en aras del bien del Estado, eran pilares que desde los Reyes Católicos habían

8. Sevilla González, M. Carmen: «Real Patronato y Santo Oficio. Conflictos entre la Inquisición y el cabildo catedral de las Islas Canarias», Revista de Inquisición, Madrid, 2009, nº. 9, pp. 69-86.

9. Tejado Fernández, Manuel: Aspectos de la vida social en Cartagena de Indias durante el Seiscientos, Sevilla, 1954, pp. 212-213.

10. Carrasco Rodríguez, Antonio: «Las intervenciones reales en los pleitos del Real Patronato», Revista de Historia Moderna, Alicante, 1997, nº. 16, p. 291.

11. Carbajal López, David: «La reforma de las cofradías novohispanas en el Consejo de Indias, 17671820», Revista Complutense de Historia de América, Madrid, 2012, vol. 38, pp. 83-84.

12. Morán, Daniel: «¿Educando a los súbditos? Modernidad y tradición en una época revolucionaria. El Investigador [del Perú] (1813-1814)», Historia Crítica, Bogotá, 2010, nº. 41, pp. 122 y 127.

13. Bravo Caro, Juan Jesús: Inquisición y religiosidad. Las cofradias de San Pedro Mártir de Verona en la España de la Edad Moderna, Cagliari, en prensa.

14. De la Hera, Alberto: «El regalismo indiano», Ius Canonicum, Pamplona, 1992, XXXII 64, p. 438, y «Reforma de la inmunidad personal del clero en Indias bajo Carlos IV», Anuario de Historia del Derecho Español, Madrid, 1960, vol. XXX, pp. 553-559. 
sido conveniente y progresivamente fortalecidos, a cambio de unas premisas ideológicas en las cuales la defensa de la fe se erigía como algo indisoluble a la defensa del Estado $^{15}$. Las medidas de supresión de órdenes religiosas y las tentativas de favorecer la disminución y mejor preparación del estamento eclesiástico tampoco alcanzaron los objetivos perseguidos, mostrando en determinadas diócesis latinoamericanas una especificidad particular al encontrarnos un clero parroquial y otro extraparroquial, «sin destino», más o menos diferenciado durante el periodo contemplado por nosotros ${ }^{16}$. Junto a todo esto, en el momento de irrupción de los movimientos insurrectos de principios del siglo XIX, las posturas de los cabildos catedralicios y del alto clero vislumbraban las propias redes clientelares que configuraban verdaderos grupos de presión o influencia construidos en la centuria anterior desde México a Chile ${ }^{17}$.

Periodo de transición, final de una época e inicio de unos años agitados de indefinición interna y exterior en el orden político, social y religioso, en cuanto al camino e importancia que debía darse a la Iglesia como institución en el nuevo marco abierto, tímidamente, entre 1810-1820, y desde ésta década en adelante sin reversión posible.

No se puede hablar de una postura unánime de la Iglesia americana ante las insurrecciones ${ }^{18}$. Es más, la propia configuración territorial y jurisdiccional repercutió en una diversa evolución hacia la Independencia, tanto en lo temporal como en lo institucional. El episcopado de las diócesis mostró una posición conciliadora respecto a los movimientos insurgentes, cuando no de apoyo decidido por parte de alguno de sus miembros, a una reestructuración del sistema de relaciones Iglesia/Roma-Estado, frente a enfoques mucho más cercanos a las directrices marcadas desde el Vaticano. Esto motivó que aquel Real Patronato establecido en América a principios del siglo XVI sería interpretado por las diversas juntas emergentes como una regalía cedida por Roma en cuanto a soberanía y no personal a los reyes que la ejercían. Por ejemplo, en Chile el debate de qué camino seguir, en cuanto a la reforma del Patronato, estuvo ausente del escenario político-eclesiástico en los primeros años de la década de $1810^{19}$. A partir de esa fecha, la misma inquietud ante los acontecimientos experimentados

15. Barrio Gozalo, Maximiliano: El Real Patronato y los obispos españoles del Antiguo Régimen (15561834), Madrid, 2004, p. 43.

16. TAYlor, William B.: Ministros de lo sagrado. Sacerdotes y feligreses en el México del siglo XVIII, tomo 1, Zamora (México), 1999, p. 114. EnRíQuez AgraZAR, Lucrecia Raquel: «El clero secular del obispado de Santiago de Chile (1700-1810)», en Rodolfo Aguirre y Lucrecia Enríquez (coords.): La Iglesia Hispanoamericana, de la colonia a la república, México, 2008, pp. 41-43.

17. Aguirre SALVAdor, Rodolfo: «Los límites de la carrera eclesiástica en el arzobispado de México (17301747)», en Carrera, linaje y patronazgo. Clérigos y juristas en Nueva España, Chile y Perú (siglos XVIXVIII), México, 2004, p. 106. EnRíQueZ, Lucrecia: «Carrera eclesiástica, Real Patronato y redes de poder en las consultas de la Cámara de Indias del clero secular chileno en el siglo XVIII», en Carrera, linaje y partronazgo. Clérigos y juristas en Nueva España, Chile y Perú (siglos XVI-XVIII)..., pp. 146-147.

18. Bushnell, David: «Las independencias comparadas: las Américas del Norte y del Sur», Historia Crítica, Bogotá, 2010, nº. 41, p. 34.

19. EnríQuez, Lucrecia: «El Patronato en Chile de Carrera a O’Higgins (1812-1824)», Hispania Sacra, Madrid, 2008, LX 122, p. 508. 
en la España peninsular, el posterior viraje político-regio con la llamada a Fernando VII y el restablecimiento del absolutismo condicionó determinadas decisiones adoptadas en dicha materia. Sin embargo, la puerta del cambio estaba abierta y sólo era cuestión de tiempo alcanzar nuevas fórmulas diplomáticas, o no, hasta llegar a las conclusiones esperadas. Pero de lo que no cabe duda es de la participación activa de parte del clero abrazando las nuevas ideas surgidas ${ }^{20}$. Es más, en la necesaria intención de justificar al pueblo las transformaciones políticas operadas, la simbología y ritual intrínsecos al estamento eclesiástico, y a sus manifestaciones exteriores, sirvieron de vehículo ejemplarizador a la ciudadanía, caso de la muestra al pueblo de volúmenes de la Constitución de 1828 en Chile ${ }^{21}$. En México, el interés del Estado por controlar los derechos inherentes al Patronato y limitar la influencia de la Iglesia, pese al apoyo decidido de muchos de sus miembros a las proclamas independentistas, reflejaba en el fondo que la nueva clase política era consciente del alcance económico y social de gestionar dicha regalía. Las controversias aparecidas encaminaron la resolución del conflicto hacia una intervención particular de los derechos del Patronato en cada Estado de la República recién creada ${ }^{22}$. En definitiva, se trataba de aprovechar los capítulos más interesantes de un regalismo monárquico obsoleto y extinguido, para transformarlo en otro de carácter republicano, que alcanzaría a las órdenes regulares en unos años de verdadero aislamiento e incertidumbre respecto a los generales de cada una de ellas y al papado ${ }^{23}$.

En verdad, coincidimos plenamente con el profesor Rodolfo Aguirre al apuntar la postura del clero, que no puede referirle una adscripción fácil a uno u otro bando ${ }^{24}$. Las circunstancias podían confundir la toma de posición de los curas cuando defendían a alguien perseguido por los realistas o los insurgentes, y la mera acción de proteger llegaría a ser elevada a posicionamientos políticos, o simplemente reivindicativos, lejos de la intención última del sacerdote. Por otro lado, el periodo 1790-1832 significó para algunas diócesis como la de La Habana, un verdadero impulso de reformas eclesiás-

20. Al respecto es muy interesante un listado de miembros del clero regular y secular, que participó en la Independencia de México entre 1808-1820: FARRISS, Nancy Marguerite: La Corona y el clero en el México colonial 1579-1821. La crisis del privilegio eclesiástico, México, 1995, pp. 235-243.

21. CID, Gabriel: «Ritos para una nueva legitimidad: ceremoniales constitucionales y republicanismo en Chile (1812-1833)», Historia Crítica, Bogotá, 2012, nº. 47, p. 33.

22. DíAz PATIÑo, Gabriela: «Los debates en torno al Patronato eclesiástico a comienzos de la época republicana: el caso de Michoacán», Jahrbuch für Geschichte Lateinamerikas = Anuario de Historia de América Latina (JBLA), Graz, 2006, 43, p. 405.

23. EnRíQueZ, Lucrecia: «Los regulares y la Independencia de Chile», en Francisco Javier Cervantes Bello, Lucrecia Enríquez y Rodolfo Aguirre Salvador (coords.): Tradición y reforma en la Iglesia hispanoamericana, 1750-1840, Puebla (México), 2011, pp. 78-79.

24. Aguirre, Rodolfo: «Sobrevivir a la insurgencia: los curas y la conservación de las parroquias. Arzobispado de México, 1813-1820», en Francisco Javier Cervantes Bello, Lucrecia Enríquez y Rodolfo Aguirre Salvador (coords.): Tradición y reforma en la Iglesia hispanoamericana, 1750-1840, Puebla (México), 2011, pp. 191-193. 
ticas en el ámbito administrativo, y los intentos más serios de mejorar el nivel de un clero escasamente preparado para afrontar las labores de catequesis ${ }^{25}$.

El escenario seguía siendo el mismo, aunque los actores canalizaban las proclamas desde el púlpito hacia un público, sus feligreses, que habían cambiado, o lo intentaban, el régimen de soberanía español por el de las incipientes repúblicas. La correcta adecuación de un Real Patronato Indiano, ejercido por la Monarquía hispánica hasta 1820, debía adaptarse a una nueva realidad surgida a partir de las diversas segregaciones territoriales, con evidentes signos de agotamiento desde mediados del siglo XVIII. Son muy claros los ejemplos de Argentina, México o Perú26. La jurisdicción de Michoacán ${ }^{27}$ es significativa en este aspecto. En el fondo, ponen de manifiesto una situación paradigmática en la propia redefinición de las relaciones de los poderes, y de la preeminencia entre ellos, de la Iglesia y el Estado, a principios de la centuria del XIX.

\section{EL DISTRITO CARTAGENERO EN LOS AÑOS DE INSURGENCIA}

El tribunal de Cartagena de Indias se instauró para aliviar a los del Perú y Nueva España, según la real orden de establecimiento ${ }^{28}$. Una amplia jurisdicción con peculiaridades propias $^{29}$, y en donde el comercio generaba riqueza, pero también planteaba problemas concretos a los cuales debía hacerse frente de manera contundente, caso del trasiego continuo de personas, con la posibilidad de propagar ideas contrarias a la religión católica, en un principio, e incluso políticas en las coyunturas convulsas de finales del siglo XVIII y principios del XIX.

La documentación recoge que por orden del 29 de septiembre de 1810 se comunicaba al tribunal del Santo Oficio de Cartagena de Indias la obligación de «reconocer y jurar la soberanía de las Cortes Nacionales y obedecer al Supremo Consejo de Regencia, con la solemnidad de misas y Te Deum..., para el acierto del nuevo gobierno cuyos patrióticos y religiosos actos se verificaron allí, sin impedimento alguno con

25. Amores Carredano, Juan Bosco y Fernández Mellén, Consolación: «La Iglesia en Cuba, 17601830», en Francisco Javier Cervantes Bello, Lucrecia Enríquez y Rodolfo Aguirre Salvador (coords.): Tradición y reforma en la Iglesia hispanoamericana, 1750-1840, Puebla (México), 2011, pp. 371-372.

26. Gallardo, Milagros: «La implementación de las leyes laicas. Una mirada sobre los discursos y las prácticas del clero. Córdoba, Argentina (1880-1890)», en Rodolfo Aguirre y Lucrecia Enríquez (coords.): La Iglesia Hispanoamericana, de la colonia a la república, México, 2008, pp. 353-378. García Ugarte, Marta Eugenia: «Provisión de las sedes diocesanas vacantes en México (1825-1831)», en Rodolfo Aguirre y Lucrecia Enríquez (coords.): La Iglesia Hispanoamericana,..., pp. 305-330. HeRnández GARcíA, Elizabeth: «De vicario eclesiástico a obispo de Trujillo: Tomás Diéguez Florencia y su adecuación al orden republicano en el Perú (1776-1845)», en Rodolfo Aguirre y Lucrecia Enríquez (coords.): La Iglesia Hispanoamericana, ..., pp. 279-303.

27. ORnelas HernándeZ, Moisés: «¿Disciplinar o castigar? Sacerdotes y política en el obispado de Michoacán (1831-1850)», en Rodolfo Aguirre y Lucrecia Enríquez (coords.): La Iglesia Hispanoamericana, de la colonia a la república, México, 2008, pp. 331-352.

28. Archivo Histórico Nacional de Madrid (A.H.N.), Inquisición, libro 352, fols. 347v-348v.

29. A.H.N., Inquisición, libro 352, fols. 356r-v. 
general aplauso y regocijo público...». La comisaría del Santo Oficio de Cuba daba constancia de la recepción y lectura del juramento, en Santiago de Cuba, 14 de mayo de $1811^{30}$. Toma de partido en la nueva situación política generada tras las abdicaciones de los monarcas españoles producidas en Bayona, y la llegada de José Bonaparte al trono hispano, con el consiguiente movimiento político frente a los franceses. En estas circunstancias se redacta en Lima un documento que presenta el clima de incertidumbre existente en los territorios americanos, incluso de la ubicación del órgano administrativo superior, del Consejo de la Suprema Inquisición en Madrid ${ }^{31}$.

La presencia en las cárceles inquisitoriales de personajes que destacarían en los procesos de independencia americanos fue habitual. En México el padre Morelos. En Lima, pese a no ser un fenómeno extendido ${ }^{32}$, destacan algunas figuras como la de Miguel Lorenzo de Vidaurre, hombre polifacético y cuyas causas emprendidas les referían desde un asiduo lector de libros prohibidos, de inspiración francesa muchas veces, hasta propagador de ideas subversivas frente al Estado colonial o la Iglesia, pasando, incluso, por invocaciones menos intelectuales caso de la solicitud de conjuros para atraer amores imposibles ${ }^{33}$.

El efecto dominó de la inestabilidad política de la metrópoli fue aprovechada por grupos insurgentes, ávidos de encontrar una mínima oportunidad para poner en marcha movimientos que desembocaran en reformas significativas en todos los órdenes de la sociedad. Cartagena de Indias no fue una excepción respecto a los brotes de insurrección, y en enero de 1812 el cariz de los acontecimientos producidos durante los últimos meses del año anterior obligó a trasladar la sede del tribunal inquisitorial a un lugar más seguro. La elegida, la ciudad de Santa Marta, era la idónea pues sus habitantes «siempre fieles y leales, en medio de las convulsiones políticas, seguían la justa causa de la nación española, defendiendo con valor los derechos santos de la Religión, Rey y Patria $»^{34}$, un bastión fiel a la monarquía española ${ }^{35}$. La búsqueda de una ubicación más

30. A.G.I., Indiferente, leg. 3014B.

31. A.G.I., Indiferente, leg. 3014B. Noticioso el tribunal de la Santa Ynquisición de Lima de la ocupación de la Corte de Madrid, por los franceses e ignorante del lugar en que reside el Supremo Consexo de la Santa General Ynquisición, se ve en la precisión de dirigir a manaos...Lima, 27 de octubre de 1809. Toda esta situación es la que hace poner sumas importantes de dinero en Cajas Reales, según exponen los autores del memorial.

32. Millar Carvacho, René: La Inquisición de Lima. Tomo III (1697-1820), Madrid, 1998, pp. 420-426.

33. Lohmann Villena, Guillermo: «Manuel Lorenzo de Vidaurre y la Inquisición de Lima. Notas sobre la evolución de las ideas políticas en el virreinato peruano a principios del siglo XIX», Revista de Estudios Políticos, Madrid, 1950, no. 52, 1950, pp. 199-216.

34. A.H.N., Inquisición, leg. 2194, exp. 8. Santa Marta, 22 de febrero de 1812. Los alborotos iniciales se produjeron, según la documentación, los días 11 y 12 de noviembre de 1811.

35. SAETHER, Steinar A.: «Independence and the Redefinition of Indianness around Santa Marta, Colombia, 1750-1850», Journal of Latin America Studies, London, 2005, nº. 37:1, pp. 68-74. SuÁReZ ArAmÉNDIZ, Miguel Antonio: «Un proceso de independencia en el caribe colombiano: Valledupar, 1810-1820», Historia Caribe, Barranquilla, 2006, n. 11, pp. 111-133. 
segura exigió asentarse un tiempo en Portobelo desde el 5 de enero de 1813 hasta el 4 de abril de $1815^{36}$.

Antes del levantamiento de noviembre de 1811 ya existían dificultades para contactar entre determinados puntos de la jurisdicción, como lo pone de manifiesto Esteban Manuel de Elosua, comisario del distrito cartagenero, quien informa al Consejo de Indias de la gran acumulación de expedientes sin poder darle curso, al permanecer cortadas las comunicaciones con Santa Fe, solicitando les indiquen a cual tribunal enviarlos ${ }^{37}$. La situación de convulsión figura en peticiones de personas que no saben a quien solicitar la declaración plena de sus derechos, una vez cumplida la sentencia impuesta por los tribunales de la Inquisición ${ }^{38}$.

Cartagena siempre aparecía como la urbe donde el tráfico mercantil era constante, además del movimiento de personas de diferentes nacionalidades. Esto supondría también un elemento clave a la hora de producirse los primeros conatos de revuelta ${ }^{39}$, aunque no existe una conclusión definitiva al debate en cuanto a la formación de un verdadero programa democrático de los insurgentes, al menos en los primeros momentos de la insurrección, a semejanza de lo planteado en otras latitudes, caso de Morelos o Artigas $^{40}$. La idiosincrasia de los colectivos activos demuestra la diversidad de adscripción grupal y motivaciones, que movieron a sus integrantes hacia la defensa de una u otra opción ${ }^{41}$. No obstante, la fragmentación inicial traía consigo la difícil labor de articular el nuevo escenario administrativo-político, surgiendo controversias entre las urbes más dinámicas por ostentar el mayor grado de autoridad sobre el resto, principalmente Cartagena y Santafé de Bogotá, en claro ejemplo de la multiplicación de la soberanía $^{42}$, desarrollando una intensa actividad diplomática ${ }^{43}$. Toda esta complejidad

36. A.H.N., Inquisición, leg. 4820, exp. 32. Santa Marta, 22 de septiembre de 1815. El documento fija «la abolición del tribunal por los ynsurgentes de Cartagena, en 28 de noviembre de $1811 »$.

37. A.G.I., Ultramar, leg. 152, $\mathrm{n}^{\mathrm{o}}$. 64. Elosua era un presbítero natural de La Habana, comisario del Santo Oficio en esa capital, y pretendiente a ministro del tribunal de la Inquisición de Cartagena de Indias, para lo cual presentó la información genealógica antes de las noticias referidas: A.H.N., Inquisición, leg. 1297, exp. 9.

38. A.G.I., Ultramar, leg. $163, n^{\circ} .83$.

39. EARLE, Rebecca A.: Spain and the Independence of Colombia, 1810-1825, Exeter, 2000.

40. GARrido, Margarita: Reclamos y representaciones: Variaciones sobre la Política en el Nuevo Reino de Granada, (1770-1815), Bogotá, 1993, p. 296; LASSO, Marixa: «Haití como símbolo republicano popular en el Caribe colombiano: Provincia de Cartagena (1811-1828)», Historia Caribe, Barranquilla, 2003, nº. 8, pp. 8-9.

41. Zuluaga, Francisco: «Clientelismo y guerrilla en el Valle del Patía, 1536-1811», en La Independencia: ensayos de Historia Social, Bogotá, 1986, pp. 111-136.

42. Restrepo Mejía, Isabela: «La soberanía del "pueblo" durante la época de la Independencia, 1810-1815», Historia Crítica, Bogotá, 2005, n’. 29, pp. 101-102; MARTínEZ GARNICA, Armando: «La agenda liberal de los Estados Provinciales de la Nueva Granada, 1810-1815», Historia Caribe, Barranquilla, 2010, n. 16, pp. 7-30; Almanza, Ángel Rafael: «El movimiento juntista de 1810 en la Capitanía General de Venezuela», Historia Caribe, Barranquilla, 2010, nº. 16, pp. 31-52.

43. Gutiérrez Ardila, Daniel: «La diplomacia “constitutiva” en el Nuevo Reino de Granada (1810-1816)», Historia Crítica, Bogotá, 2007, n. 33, pp. 38-72. 
social ha llevado a diversos autores a un replanteamiento historiográfico, y discutir sobre la verdadera dimensión y concreción de los fenómenos políticos experimentados en los albores del XIX -Independencia-Emancipación ${ }^{44}$-, destacando en los mismos la participación sobresaliente de elementos extranjeros en calidad de dirigentes frente a la metrópoli ${ }^{45}$. Además, las presiones de las Cortes de Cádiz, en un contexto bastante enrarecido en tierras del reino de Nueva Granada, tampoco ayudaron a canalizar esfuerzos conjuntos tendentes a posicionamientos unánimemente aceptados por las élites de las ciudades principales ${ }^{46}$. Es más, la Junta de Cartagena no habría adoptado una actitud beligerante al principio, con un viraje sin retorno tras sentirse vilipendiada en la institución gaditana ${ }^{47}$, «mas, presto conocimos que las mismas cortes no estaban esentas del carácter falaz que a distinguido a los gobiernos revolucionarios de España» ${ }^{48}$. Las expectativas despertadas por las Cortes gaditanas desatendieron muchas reivindicaciones planteadas desde los distintos grupos étnicos y sociales americanos ${ }^{49}$.

De hecho, los movimientos segregacionistas de la parte más septentrional del continente americano servirían de iluminación para los llevados a cabo con posterioridad en la franja central y meridional, además de alimentar los primeros intentos serios de independencia. No obstante, el «enfoque atlántico» sería incapaz de dar una explicación totalmente convincente, por sí solo, del proceso de emancipación llevado a cabo en los reinos bajo soberanía española, y en las consecuentes independencias, dado que estamos examinando movimientos muy complejos, con pervivencias del pasado escasamente rompedoras de instituciones vigentes en esos años iniciales de la centuria del ochocientos, hasta $1825^{50}$. En este sentido, la Inquisición manifestará un apoyo incon-

44. Acosta, Vladimir: Independencia y Emancipación. Élites y pueblo en los procesos independentistas hispanoamericanos, Caracas, 2010; HÉBRARD, Véronique: Venezuela independiente. Una nación a través del discurso (1808-1830), Madrid, 2012; BrEÑA, Roberto: El imperio de las circunstancias. Las independencias hispanoamericanas y la revolución liberal española, Madrid, 2012.

45. Chauca García, Jorge: «El grupo irlandés entre el siglo XVIII y XIX: su papel en la Ilustración e Independencia americanas», en Enrique García Hernán y Óscar Recio Morales (coords.): Extranjeros en el ejército. Militares irlandeses en la sociedad española, 1580-1818, Madrid, 2007, pp. 351-378.

46. MúnerA, Alfonso: Failing to Construct the Colombian Nation: Race and Class in the Andean-Caribbean Conflict, 1717-1816, Ph. D. dissertation, University of Connecticut, 1995, pp. 174-211, y «El Caribe colombiano en la república andina: Identidad y autonomía política en el siglo XIX», Boletín Cultural y Bibliográfico, Bogotá, 1996, vol. 33, nº. 41, pp. 29-49.

47. González Arana, Roberto y Monsalvo Mendoza, Edwin: «De la Suprema Junta de Gobierno al Estado soberano. La independencia de Cartagena de Indias (1810-1812)», Historia Crítica, Bogotá, 2010, n'. 41, p. 62.

48. Acta de Independencia de la Provincia de Cartajena en la Nueva Granada. Palacio de Gobierno de Cartagena de Indias, 11 de noviembre de 1811 «el primero de nuestra independencia». Imprenta de Echeverría Hermanos. Museo Nacional de Colombia. Número de registro 728.

49. Chauca Garcia, Jorge: «Indígenas e ilustrados: pensamiento y práctica en la búsqueda del consenso imperial hispano», en La época de Carlos IV (1788-1808). Actas del IV Congreso Internacional de la Sociedad Española de Estudios del Siglo XVIII, Oviedo, 2009), pp. 327-337.

50. BreÑA, Roberto: «Presentación. Las independencias americanas. La revolución española y el enfoque atlántico», Historia y Política, Madrid, 2010, n. 24, pp. 16-21. 
dicional, como no podía ser de otra manera, al dominio español en todos los territorios bajo su jurisdicción. Sin embargo, aunque la institución mantuvo una decidida apuesta por la causa española, los miembros que la componían expresarán diversas actitudes.

Lograda la independencia de la Nueva Granada, la Iglesia persiguió recuperar un terreno que consideraba bajo su potestad, y evitar un distanciamiento excesivo del Estado, sin renunciar a derechos concretos, en especial cuando parte del clero mostró su discrepancia más airada, incluso mediante las armas, frente a la dominación española ${ }^{51}$. La fecha de 1820 es el punto de inflexión de las relaciones de la Iglesia católica latinoamericana y los nuevos Estados emergentes, a raíz de los decretos que en materia económica, de representatividad y de limitación de privilegios lesionaban los intereses del clero en su totalidad ${ }^{52}$. Aunque todavía estaba lejos de apartarse por completo de la escena pública-política, si observamos ejemplos como el de Manuel Benito Rebollo, cura cartagenero delegado por Colombia en la reunión organizada por Bolívar a la hora de proyectar la Confederación Andina en $1825^{53}$. Al juego, tanto del Estado como de la Santa Sede, por aprovechar una coyuntura en la cual aquel quería hacer suyos ciertos fundamentos de la regalía del Patronato, y Roma pretendía recuperar unos derechos cedidos durante siglos a España, se le intentó dar una solución estable a raíz de la llegada al papado de Gregorio XVI, incluso antes de su pontificado, aunque no estuvo exento de problemáticas concretas y generales ${ }^{54}$.

El restablecimiento de la Inquisición vería reforzada la alianza del tribunal con la monarquía, y una fórmula era aprovechar la experiencia secular en investigar los casos de herejía para reconducirla ahora hacia las personas implicadas en los levantamientos sufridos en las jurisdicciones respectivas. De esta forma, muchas causas tuvieron protagonistas acusados de comportamientos no demasiado acordes con los principios establecidos en un orden social de las características del implantado. Una de ellas recoge el expediente abierto en 1817 contra el contador don Lázaro María de Herrera, al objeto de «purificar su conducta durante la revolución, porqué se quedó en la plaza de

51. Marín TAMAYO, John Jairo: «La convocatoria del primer Concilio neogranadino (1868): un esfuerzo de la jerarquía católica para restablecer la disciplina eclesiástica», Historia Crítica, Bogotá, 2008, nº. 36, pp. 174-193.

52. Para el ámbito colombiano contamos con un reciente e interesante trabajo de CortÉs GUERRERO, José David: «Balance historiográfico sobre las relaciones Estado-Iglesia en Colombia desde la Independencia hasta finales del siglo XIX», Historia y Sociedad, Medellín, 2010, nº 18, pp. 163-190.

53. Mora MéridA, José Luis: «Ideario laicista-masónico e Iglesia católica en la formación de las nacionalidades hispanoamericanas», en José Antonio Ferrer Benimeli (coord.): La masonería española entre Europa y América. VI Symposium Internacional de Historia de la Masonería Española, I, Zaragoza, 1995 , p. 522.

54. López V., Álvaro: Gregorio XVI y la reorganización de la Iglesia Hispanoamericana. El paso del régimen de patronato a la misión como responsabilidad directa de la Santa Sede, Roma, 2004, pp. 236-239, 345-378. 
Cartagena de Indias cuando el tribunal se marchó ${ }^{55}$. La del secretario del secreto, don Fermín Paniza y Navarro, tuvo la misma naturaleza ${ }^{56}$.

El aparato burocrático garantizaba una nueva etapa de apoyo a la Monarquía, y la unión debía constituirse de manera más estrecha por los episodios vividos y del germen revolucionario que impregnaba a toda América. Este sentimiento encerraba uno de tantos pronunciamientos insertos en la documentación inquisitorial, cuando habla «de la autoridad y potestad que los Papas y Reyes tienen concedidos al Santo Oficio de la Ynquisición cuyo zelo en promover la gloria de Dios y sostener los derechos del govierno monárquico...» ${ }^{57}$.

\section{EL COMPLEJO MUNDO DE LAS COMPETENCIAS}

El establecimiento del tribunal en Cartagena de Indias venía avalado por la excesiva dimensión de las jurisdicciones de los creados en Lima y México. La ciudad cartagenera aparece continuamente en las justificaciones para la erección y a lo largo de la existencia de su distrito a partir de 1610, como «puerto de mar, tan abierto, donde concurren de todas las naçiones del mundo, y a donde la gente es más liçenciosa y libre que la de otros lugares de la tierra adentro» ${ }^{58}$. Estas problemáticas volverán a surgir con fuerza en el transcurso de los acontecimientos vividos a principios del siglo XIX, y servirá de arma arrojadiza cuando determinados autores hagan mención de la facilidad a la hora de circular obras prohibidas y perseguidas por las disposiciones vigentes en ese tiempo. Pese al entusiasmo inaugural, en el transcurso de su existencia los obstáculos encontrados hicieron plantear la disolución del mismo, pues eran innegables las disputas internas y «los inconvenientes que se suelen ofrecer en las inquisiciones ultramarinas» por la distancia respecto al centro final de decisiones ${ }^{59}$. A lo largo de 1610, aprovechando la erección del nuevo tribunal y para evitar fricciones con otros distritos, se establecen una serie de normas, de obligado cumplimiento por todas las partes, al objeto de prevenir los tan habituales conflictos de competencias a los cuales nos referiremos en las páginas siguientes ${ }^{60}$.

El tribunal cartagenero tuvo que hacer frente a las transgresiones en materia de fe, y a incidentes impensables, a priori, como los emanados de la Iglesia, que en el fondo representaban una lucha por el poder en el seno de las comunidades donde debían ejercer sus funciones. De esta forma se abrió información en 1612 sobre la actividad del obispo de Cartagena, don Alonso Enríquez de Toledo, quien alentaba a los feligreses

55. A.H.N., Inquisición, leg. 2194, exp. 14.

56. A.H.N., Inquisición, leg. 2194, exp. 15.

57. A.H.N., Inquisición, leg. 2194, exp. 13.

58. A.H.N., Inquisición, leg. 1597, exp. 14. Cartagena, 17 de julio de 1628.

59. A.H.N., Inquisición, leg. 1605, exp. 15. Autos sobre la decisión del inquisidor Juan Ortiz de Zárate, de cerrar el tribunal. Años 1688-1690.

60. Ejemplo de ello sería la Real Cédula comunicada a la Audiencia de Santo Domingo, fechada el 22 de mayor de 1610. A.G.I., Santo Domingo, 869, L.6, fols. 80r-v. 
a manifestar ante la autoridad eclesiástica secular, y no en la inquisitorial, prácticas heréticas concretas al objeto de obtener una sentencia menos severa: «luego que llegó a la villa del Bayamo, en algunas pláticas que propuso en la iglesia a dado a entender que tuviesen algunos crímenes de herejías o hechicerías se los manifestasen que él, con blandura, los repararía antes que el Santo Oficio metiese en ello la mano» y «como padre usaría con ellos de misericordia y con un papel que el les diese, pareçiendo que avían conpurgado sus culpas, los señores ynquisidores no proçederían contra ellos, y en defecto de no lo hacer vendría mañana la Inquisición y se berían con grandes mohinas o desventuras ${ }^{61}$. Las divergencias con el episcopado brotarían por diversos temas, en contextos con implicación de otras administraciones, caso de la Audiencia ${ }^{62}$.

Los conflictos con otros poderes civiles y eclesiásticos del momento reproducían enfrentamientos seculares, mucho más visibles en tales circunstancias. La precedencia o la preeminencia jugaban un papel bastante fundamental ahora. Por otro lado, las fricciones entre instituciones fueron una constante a lo largo del siglo XVIII, y cualquier ocasión era buena para que la Corona aportara el equilibrio necesario para la marcha efectiva de los territorios bajo su soberanía, máxime cuando defendía, en el fondo, a grupos cuya fidelidad demostraban continuamente, caso de la resolución de una disputa suscitada a principios de la centuria mencionada entre el alto clero mexicano y el colegio de Santos ${ }^{63}$.

Además, la extinción temporal del Santo Oficio, y luego definitiva, servirán para visualizar las propias luchas internas de poder de una institución paraestatal, anacrónica en la época de transición de los siglos XVIII y XIX con el despertar de sentimientos nacionales, satisfactoriamente canalizados por una parte de la población, y que tenían a la Inquisición como un elemento perverso de la dominación española llevada a cabo a lo largo de siglos.

Al contenido del Real Patronato acudían siempre que surgían disputas entre instituciones civiles y eclesiásticas, o la Inquisición. Así se formalizaron autos del gobernador de Venezuela, Francisco de la Hoz Berrio, contra el comisario inquisitorial en Santiago de León, por abuso de jurisdicción, en los años 1618-1619. Figura la denuncia del obispo don Fray Juan de Bohórquez por continuos roces y al escaso respeto al texto de «las Reales Cédulas y Patronasgo de su majestad» ${ }^{64}$. Estamos en una etapa inicial de establecimiento del tribunal en Cartagena de Indias, y los enfrentamientos comienzan a ser una tónica general, muchas veces llevados a los tribunales correspondientes ${ }^{65}$. Uno

61. A.H.N., Inquisición, leg. 1597, exp..16. Cartagena de Indias, 12 de marzo y 29 de abril de 1612.

62. A.H.N., Inquisición, leg. 1599, exp. 5. Año 1715.

63. Aguirre, Rodolfo: «El conflicto del alto clero de México con el colegio de Santos y la corona española (1700-1736)», en Rodolfo Aguirre y Lucrecia Enríquez (coords.): La Iglesia Hispanoamericana, de la colonia a la república, México, 2008, pp. 257-258.

64. A.H.N., Inquisición, leg. 1597, exp. 2.

65. A.G.I., Santa Fe, leg. 495. Expedientes sobre las controversias surgidas entre el obispo de Cartagena, Miguel Antonio Benavides y Piédrola, con el inquisidor de aquella capital, Francisco de Varela. Años 1684-1709. 
de los pleitos de competencias se suscitó con la Audiencia de Santa Fe, en la causa de Martín de Rojas, alguacil mayor de la Inquisición de Tunja (Colombia), en el periodo $1669-1673^{66}$.

A veces los litigios tenían origen en la decisión de alguno de los inculpados, cuando optaban por acudir a la justicia real o la inquisitorial, buscando la sentencia más liviana en las cuestiones que motivaban el apresamiento. Esta circunstancia generaba, por consiguiente, el choque de las instituciones responsables en abrir la causa, especialmente en situaciones de desorden público, donde la Audiencia tenía competencias delegadas, aunque los miembros del Santo Oficio intentaban siempre ser procesados en su tribunal ${ }^{67}$.

Las desavenencias por cuestiones de etiqueta fueron episodios de desencuentro, incluso, entre oficiales de la propia Inquisición. Prueba de ellos son los autos redactados en el conflicto del notario de secuestro Martín de Escobar Ibáñez y Diego Martínez Hidalgo, contador, al pretender el primero ocupar en 1658 «el banco cubierto de oficiales titulares ${ }^{68}$. También Pedro Calderón Gallego, alguacil mayor, y Miguel de Echarri y Díaz, secretario del secreto, tuvieron que dirimir sus diferencias ante el tribunal inquisitorial pues aquel decía que el segundo ocupaba su parte de banco «en la cabecera... que su extremidad llegava a la tarima sobre que están puestas las sillas de los señores ynquisidores devajo del dosel» ${ }^{69}$. Esta problemática, la de sentarse en un lugar destacado, constituía una fuente de discordia en cualquier órgano administrativo, celebración o festividad pública, y no dejarán de sucederse a lo largo de los siglos XVII al XIX. En ciertas ocasiones, los memoriales aluden a la falta de ubicación en las solemnidades realizadas en el interior de edificios emblemáticos, como en la Catedral de La Habana, cuando los oficiales denuncian no tener señalados asientos específicos para ellos ${ }^{70}$.

El problema de las competencias siempre estaba presente, y no solo en las relaciones entre los poderes civiles y eclesiásticos, si no en el interior de lo comprendido en este último grupo ${ }^{71}$. Los conflictos abarcarían temas de diversa naturaleza: gestión y recaudación de patronatos y capellanías, ingresos de canonjías, causas de fe, fuero de ministros, competencia en causas civiles y criminales, cuestiones de etiqueta, protocolo y preeminencia, requisitorias de causas... No habrá excepciones en la evolución de

66. A.H.N., Inquisición, leg. 1597, exp. 6.

67. A.H.N., Inquisición, leg. 1597, exp. 9. Años 1668-1674.

68. A.H.N., Inquisición, leg. 1597, exp. 5.

69. A.H.N., Inquisición, leg. 1597, exp. 8. Años 1683-1685.

70. A.H.N., Inquisición, leg. 1597, exp. 10. Años 1658-1659.

71. Maqueda Abreu, Consuelo: «Los conflictos de competencias. Una muestra en el tribunal inquisitorial de Nueva España», Cuadernos del Instituto de Investigaciones Jurídicas, México, 1998, p. 334. 
los diferentes tribunales erigidos, ya sea en $\operatorname{Lima}^{72}$, México ${ }^{73}$ o Cartagena de Indias ${ }^{74}$, y las recopilaciones jurídicas coetáneas recogen la normativa decretada para impedir cualquier tipo de disputa ${ }^{75}$. En México confeccionaron un ordenamiento judicial autónomo del Santo Oficio, cuya vigencia llegó al Tercer Concilio Mexicano. Pero las ingerencias del tribunal inquisitorial, tanto en las jurisdicciones mexicanas como en otras zonas americanas, mantuvieron el pulso durante siglos, a veces difíciles de superar desde el momento que determinados miembros del clero aunaba responsabilidades de comisarios inquisitoriales y jueces eclesiásticos ${ }^{76}$. La postura de las nuevas naciones hacia la Iglesia, y todo lo que ésta representaba, también tendría una visualización nada baladí en el carácter simbólico desplegado en las celebraciones públicas, en un intento de relegar a un segundo plano el papel del estamento eclesiástico respecto al civil y el militar, muy unido en ocasiones ${ }^{77}$.

El Decreto de extinción de 22 de febrero de 1813 obligó a redactar los pertinentes informes de inventario y traslado de documentación y bienes. En Cartagena inician con prontitud las tareas y en Lima llevan los papeles del tribunal de la Inquisición al arzobispado (8 de septiembre de 1813), contabilizando las propiedades, y cualquier cuestión relacionada con la gestión económica de dichos tribunales ${ }^{78}$. El 21 de julio de 1814 se restablecen los tribunales «al pie y estado en que se hallava el año de 1808», y desde el cartagenero, en concreto de Santa Marta, el 28 de abril de 1815, enviaban una carta al inquisidor general «deseoso dicho tribunal de manifestar a vuestra señoría ilustrísima la particular complacencia de la acertada elección que ha hecho su majestad» ${ }^{79}$.

La ley que restablecía los tribunales de la Inquisición era muy explícita a la hora de fijar «que en puntual observancia de la ley i, título XIX, libro I de la Recopilación de

72. Millar Carvacho, René: La Inquisición de Lima. Tomo III..., pp. 107-151, y «Los conflictos de competencia de la Inquisición de Lima», en Congresos del Instituto de Historia del Derecho Indiano [Archivo de ordenador]: actas y publicaciones, vol. 4, 2000 (VIII Congreso Internacional de Historia del Derecho Indiano. Tomo II), pp. 95-128.

73. Maqueda Abreu, Consuelo: Estado, Iglesia e Inquisición en Indias. Un permanente conflicto, Madrid, 2000, pp. 65-186.

74. Álvarez Alonso, Fermina: La Inquisición en Cartagena de Indias durante el siglo XVII, Madrid, 1999 , pp. 34-38.

75. De Solórzano Pereira, Juan: Politica indiana sacada en lengua castellana de los dos tomos del Derecho i govierno municipal de las Indias Occidentales..., Madrid, 1648, libro IV, capítulo XXIV, pp. 702-714.

76. Aguirre Salvador, Rodolfo: «El establecimiento de jueces eclesiásticos en las doctrinas de indios. El arzobispo de México en la primera mitad del siglo XVIII», Historia Crítica, Bogotá, 2008, n. 36, pp. 17 y 27.

77. Valenzuela Márquez, Jaime: «La militarización de las celebraciones públicas en el Chile de los Borbones y la Independencia», Revista Complutense de América, Madrid, 2011, vol. 37, pp. 185 y 191.

78. Como ejemplo de la documentación generada tendríamos los expedientes enviados a las distintas autoridades competentes, referidos al tribunal de Cartagena de Indias, Isla de Cuba de los años 1819-1824 (A.G.I., Santo Domingo, 2279), y al correspondiente al Santo Oficio del Perú (A.G.I., Lima, 1605, y A.H.N., Inquisición, leg. 4800, exp. 1. Ambos están formalizados en el bienio 1813-1814).

79. A.H.N., Inquisición, leg. 1605, exp. 14. 
Indias, los vireyes, como vice-patronos reales, protejan los tribunales del Santo Oficio, auxiliando la cobranza de sus deudas, ya sea contra cuerpos o ya contra particulares $»{ }^{80}$. En cuanto al otro foco de fricciones, el episcopado, no duda de la buena predisposición de arzobispos y obispos para dejar «espedita» la jurisdicción de la Inquisición «para que contribuyendo por la suya a conservar la armonía que siempre han tenido con estos tribunales se destierre hasta la sombra de la menor competencia». En cuanto a las Audiencias y justicias reales, recordaban que los inquisidores y sus ministros estaban bajo la protección real.

\section{MASONERÍA: PRESENCIA Y REPRESIÓN}

«Yo he visto á los franc-masones aplaudidos en unos paises, despreciados en otros, y perseguidos en muchos. ¿De que ha podido provenir, exclamé yo, esta variedad en los sentimientos y conducta de las naciones? ¿Como pueden unas juzgar bueno ó indiferente lo que otras consideran peligroso ó despreciable? todo es publico en el pais en que resido: los franc-masones son favorecidos en él; y sus catecismos y libros corren impresos, y se encuentran doquiera» ${ }^{81}$.

Este párrafo contrasta con el siguiente:

«Siempre hubo y habrá malos en el mundo; pero tantos, tan unidos, y conspirados por sistema para trastornar todos los gobiernos y aniquilar, si fuera posible, la santa Iglesia católica romana, no los hubo jamás, estaba reservada para estos últimos tiempos

El mundo está inundado de franc-masones, publicos en todo el Imperio frances, ocultos en España, Italia, Alemania, Turquia, Asia, Africa y América. El proyecto de estos sectarios en regenerar el mundo, estableciendo en todas partes el Reyno de la Filosofia, o de la libertad de conciencia, esto es, el deismo, ateismo, naturalismo o bestialismo, que todo es uno. Para conseguir el intento es necesario remover dos grandes obstáculos, la Religión revelada y la monarquia católica, las quales se sostienen mutuamente. Los medios de que siempre se han valido, y se valen para arruinar la Religión y la Monarquia son: la disension entre ambas potestades; las disputas de jurisdicción eclesiástica y civil, del Papa y de los Obispos.... $\rangle^{82}$.

El autor los asocia con una «cábala infernal» que es necesario extirpar de la sociedad, pero que está inserta en todas las naciones, aunque no causan alarma alguna. Reunidos en una logia o «club, donde hacen muchas ridiculeces, supersticiones y profanaciones». Continúa diciendo que «no todos los filósofos son franc-masones, pero todos los franc-masones son filósofos, o por mejor decir sofistas».

Pese a los comentarios del escritor referido en las líneas precedentes, que en definitiva recogía el sentir de muchos enemigos de tal forma de asociación, resulta un tanto

80. A.G.I., Indiferente, leg. 3014B. Madrid, 31 de julio de 1815.

81. Cabral de NoroÑa, Miguel: Reflexiones imparciales sobre la francmasonería, Filadelfia, 1818, pp. 3-4.

82. López, Simón: Despertador christiano=politico. Se manifiesta que los autores del trastorno universal de la Iglesia, y de la Monarquía son los filósofos franc-masones: se descubren las artes diabólicas de que se valen, y se apuntan los medios de atajar sus progresos, Murcia, 1808-1810¿?), III, XXXIII-XXXIV. 
contradictoria la fórmula de juramento al realizar los ritos de iniciación, pues siempre se comprometían, en la gran mayoría de las logias, a mantener la fidelidad al rey, a los principios regios, y a la religión ${ }^{83}$. No obstante, la «amenaza» podía ceñirse sobre cualquier tipo de régimen, lo cual hacía a la masonería estar en el punto de mira de monarquías o repúblicas, ya fueran católicas, protestantes o islámicas. Así tendremos que las primeras prohibiciones las ordenan los Estados Generales de Holanda (1735), El Consejo de la República y Cantón de Ginebra (1736), Luis XV en Francia (1737) y los magistrados de la ciudad de Hamburgo (1738). En éste último año será la «Corte de Roma» quien añadirá las nuevas proscripciones a un largo texto normativo de carácter condenatorio, restrictivo y represor.

El 11 de octubre de 1738, el inquisidor general Andrés de Orbe y Larreátegui prohibía oficialmente la masonería, aunque en verdad los tribunales no sabían a ciencia cierta cuales eran las características de esta nueva herejía ${ }^{84}$. Unos seis meses antes, el Papa Clemente XII la había condenado formalmente, y el 18 de mayo de 1751 su sucesor, Benedicto XIV, ratificaba el texto precisando algunos términos, y hasta la siguiente prohibición de 1821 tendría vigencia en la esfera católica ${ }^{85}$. El carácter espiritual de lo dispuesto en Roma recogería la esencia política de una decisión de esas características, en el tránsito de la etapa colonial a la de los procesos de emancipación/independencia.

La documentación inquisitorial ofrece noticias a cerca de aspectos muy concretos de las personas procesadas -edad, status social, relaciones familiares y profesionales, motivaciones para entrar en la logia correspondiente, etc.-, que complementa la información de otras fuentes. A partir de las relaciones de causas algunos investigadores han concluido la escasa presencia de denuncias a masones en los tribunales españoles, y coinciden en señalar dos puntos principales a la hora de delatar y considerar a estas personas como algo negativo para la sociedad de la época: el secreto impuesto en sus actuaciones junto a la labor obligatoria de ayuda a los grupos más indigentes ${ }^{86}$. El primero de ellos, paradójicamente, es destacado por ciertos investigadores de elemento atractivo para muchos miembros del clero cuando decidían entrar en una logia.

La primera persona en España que consta documentalmente su proceso por delito de masonería, juzgado y castigado en el Tribunal inquisitorial de Corte, fue el clérigo

83. Ferrer Benimeli, José Antonio: La masonería, Madrid, 2002, pp. 31-33 y 60.

84. Ferrer Benimeli, José Antonio: Los archivos secretos vaticanos y la masonería, Caracas, 1976, p. 169.

85. Ferrer Benimeli, José Antonio y CAprile, Giovanni: Masonería e Chiesa católica, ieri, oggi e domani, Roma, 1979, pp. 13-14. Los textos pontificios promulgados en la época tratada aquí, además de los dos reseñados para el siglo XVIII, serían los de 13 de septiembre de 1821 (Pío VII), y de 13 de marzo de 1825 (León XII).

86. Martínez Millán, José: «Sociología de los masones españoles a través de las relaciones de causas inquisitoriales: 1740-1820», en José Antonio Ferrer Benimeli (coord.): La masonería en la Historia de España: Actas del I Symposium de Metodología Aplicada a la Historia de la Masonería Española, Zaragoza, 1985, pp. 35-36. 
Francisco de Roscobet, en $1744^{87}$, sentenciado al destierro «perpetuamente de todos los Reynos de España» ${ }^{88}$.

Si para la España de la Península Ibérica la presencia de la masonería es más bien tardía, respecto a otras monarquías y repúblicas del siglo XVIII, los territorios coloniales bajo su soberanía no iban a ser una excepción. Muchos autores creen más acertado calificar de existencia de masones aislados, pero no de la formación de logias antes de $1800^{89}$. El desarrollo de las estructuras internas se iniciaría a partir de las décadas siguientes a $1810^{90}$, formando parte sus miembros de la oficialidad militar y estableciendo contactos con la masonería norteamericana o francesa ${ }^{91}$. Uno de los primeros datos conservados nos retrotrae a la Cuba del bienio 1762-1763, cuando la presencia inglesa dejaría huella en este sentido, una vez abandonada la isla ${ }^{92}$, aunque el conflicto hispano-francés de 1808 abriría un proceso en el espacio cubano donde las logias multiplicaron su presencia ${ }^{93}$. Si atendemos a la documentación inquisitorial, para Lima y México las denuncias iniciales quedan recogidas a partir de $1755^{94}$, y pese a no ser numerosas muestran la dificultad de controlar una forma de asociacionismo sin perfiles claros de herejía. En el tribunal cartagenero, en concreto en la ciudad de Caracas, toda vez que dicha jurisdicción sufrió ciertos traslados en el transcurso de las revueltas de principios del siglo XIX, fue incoado un expediente a varias personas acu-

87. Ferrer Benimeli, José Antonio: Masonería, Iglesia e Inquisición: un conflicto ideológico-politico-religioso. II. Inquisición: Procesos históricos (1739-1750), Madrid, 1976), p. 231.

88. A.H.N., Inquisición, libro 1168, fols. 201-202.

89. Navarrete, Félix: La masonería en la Historia y en las leyes de Méjico, México, 1957, p. 31. Para este autor, la masonería inicia su trayectoria en el territorio mexicano desde 1806.

90. Danton, Georges Jacques: Historia general de la masonería: desde los tiempos más remotos hasta nuestra época: sus origenes, sus causas, IV, A Coruña, 2002, p. 466; MARTínez DE Codes, Rosa María: «El impacto de la masonería en la Legislación Reformista de la primera generación de liberales en México», en José Antonio Ferrer Benimeli (coord.): Masonería española y América. V Symposium Internacional de Historia de la Masonería Española, I, Zaragoza, 1993, pp. 129-145.

91. Del Solar Guajardo, Felipe Santiago: «José Miguel Carrera. Redes masónicas y sociedades secretas durante las guerras de independencia en América del Sur», en José Antonio Ferrer Benimeli (coord.): La masonería española. Represión y exilios. XII Symposium Internacional de Historia de la Masonería Española, I, Zaragoza, 2010, p. 495.

92. Miranda Álvarez, Aurelio: Historia documentada de la masonería en Cuba, La Habana, 1933, pp. 13-14.

93. Torres-Cuevas, Eduardo: «Los cuerpos masónicos Cubanos durante el siglo XIX», en José Antonio Ferrer Benimeli (coord.): Masonería española y América. V Symposium Internacional de Historia de la Masonería Española, I, Zaragoza, 1993, pp. 233-234; Ferrer Benimeli, José Antonio: «Apuntes históricos de la masonería cubano-española del siglo XIX», en José Antonio Ferrer Benimeli (coord.): Masonería española y América...., I, pp. 345-348.

94. Ferrer Benimeli, José Antonio: Masonería e Inquisición en Latinoamérica durante el siglo XVIII, Caracas, 1973, pp. 21-28. 
sadas de francmasones ${ }^{95}$. Este caso estudiado por Henar Pizarro ${ }^{96}$, no seria el único. La influencia de las logias procedentes de Jamaica parece estar constatada en Cartagena de Indias ${ }^{97}$, en una red que desde puntos estratégicos abordarían determinados espacios geográficos cada vez más convulsos, y propicios a formalizar reformas.

A este clima en el que las delaciones tomaban un cariz político-ideológico encuadramos algunas denuncias presentadas ante el Santo Oficio. Las mismas alcanzaban hasta altos cargos de la administración eclesiásticas, caso del obispo de La Habana, Juan José Díaz de la Espada, acusado de masón el 18 de noviembre de $1815^{98}$, en una ciudad donde la formación de asociaciones de «libertinos» era manifiesta ${ }^{99}$.

\section{CONTROL DE IDEAS Y PROHIBICIÓN DE LIBROS}

«Es indudable que la lectura de libros prohibidos ha ocasionado en todos tiempos la corrupción de costumbres y trahido incalculables perjuicios a la Santa Religión Católica y a la soberanía baxo tal concepto, el exponente ejercitado en el cumplimiento de su sagrado ministerio y comisión ha vigilado infatigablemente para impedir el uso pernicioso daquellos, y así es que recogió innumerables. En comprobación de esta verdad, y de su zelo, reduxo a cenizas públicamente, en sólo una vez, tres mil setecientos volúmenes, fuera de otras de cuya operación elevó cuenta a la superioridad del distrito» ${ }^{100}$.

El párrafo antecedente, presentado en abril de 1816 por el doctor don Esteban Manuel de Elósua, presbítero e inquisidor apostólico honorario del tribunal de Cartagena de Indias, y comisario principal, propietario, en la ciudad de La Habana, es muy explícito por sí solo. El vanagloriarse de una acción como la descrita resaltaría la figura de este individuo ante la autoridad inquisitorial de quien dependía, y ponía sobre el papel la recuperación de una actividad que seguía teniendo todavía vigencia pese a encontrarse en el tramo final de su existencia. Relacionaba estrechamente las escasas competencias que tenía con el clima de «libertinaje» extendido, y por ello proponía la erección de un tribunal en la capital habanera, independiente de Cartagena de Indias. Palabras y canciones de mal ejemplo para los menores serían algo cotidiano, y el estado alcanzado había obligado al obispo a prohibir los tradicionales rosarios nocturnos,

95. A.H.N., Inquisición, leg. 3722, exp. 219. Expediente formado en Caracas contra varios individuos del ejército espedicionario por francmasonería. Año 1817.

96. Pizarro Llorente, Henar: «La Represión de la masonería en el Tribunal del Santo Oficio de Cartagena de Indias a principio del s. XIX», en José Antonio Ferrer Benimeli (coord.): Masonería española y América..., I, pp. 62-70.

97. Seal-Coon, Frederic William: «La Isla de Jamaica y su influencia masónica en la Región», en José Antonio Ferrer Benimeli (coord.): Masonería española y América...., I, p. 208. El autor señala en concreto la logia denominada Las Tres Virtudes Teologales.

98. A.H.N., Inquisición, leg. 2194, exp. 12. Este documento está estudiado en Martínez MiLlán, José: «Juan José Díaz de la Espada, Obispo de La Habana, ¿Un prelado masón?», en José Antonio Ferrer Benimeli (coord.): Masonería española y América...., I, pp. 50-55.

99. A.G.I., Indiferente, leg. 3014B.

100. A.G.I., Indiferente, leg. 3014B. La Habana, 29 de abril de 1816. 
pues llegaron a atacar hasta los vía crucis de los viernes de Cuaresma con la intención de sustraer las joyas portadas por las imágenes.

En la línea de lo anterior, en cuanto a la estrecha relación de lecturas peligrosas y revueltas, es muy rotundo el párrafo que le dedica el fiscal del tribunal inquisitorial de Cartagena de Indias en junio de 1815, al referirse a un Catecismo elaborado por un sacerdote, de cuyo contenido hablaremos más adelante:

«Con el motivo de la ynsurrección e yndependencia de lo más del distrito y extinción del tribunal se ha franqueado puerta muy ancha a todos los perversos criminales revolucionarios ynsurgentes, no solo para introducir libros obsenos y perniciosos, sino también para leerlos, retenerlos y propagarlos por todas partes para conseguir sus depravados y diabólicos fines» ${ }^{101}$.

El Consejo de Castilla era quien tenía la máxima potestad a la hora de controlar la edición de manuscritos en los territorios españoles. Por su parte, el Consejo de la Suprema Inquisición siempre tuvo interés en participar de estas competencias, o al menos de ejercer una estrecha vigilancia de lo ya publicado. Los sucesivos edictos de condenaciones, plasmados en índices periódicos de libros prohibidos son buena prueba de ello. En el contexto convulso del último Borbón de la Edad Moderna hispana, y la irrupción de las ideas revolucionarias foráneas, habitualmente francesas junto a las propias de los reinos emergentes, la actividad no decaería, máxime cuando los tribunales inquisitoriales fueran restaurados por Fernando VII. Determinadas personas contaron con la licencia preceptiva para leer determinados títulos editados, pese a estar insertos en los listados mencionados. El perfil de los autorizados casi siempre coincidía con elementos del estamento eclesiástico, aunque personalidades u hombres de influencia recibirían los permisos correspondientes, lo cual planteaba verdaderos embarazos cuando eran colaboradores cercanos a los máximos representantes del poder real en sus colonias, caso del doctor Ramón de Rozas, asesor de Ambrosio O’Higgins ${ }^{102}$, en sus etapas de gobernador en Chile, primero, y posteriormente virrey en Lima ${ }^{103}$. Pero tales autorizaciones podían ser revocadas en el marco de inestabilidades sociales o políticas como las experimentadas durante los años 1795-1820. Incluso, las medidas llegaban a ser muy extremas, hasta el punto de ordenar desde el Consejo de la Suprema Inquisición a deshacerse físicamente de todos los volúmenes prohibidos conservados en los tribunales de distrito ${ }^{104}$.

101. A.H.N., Inquisición, leg. 1605, exp. 9. Santa Marta, 27 de junio de 1815.

102. Sobre la figura de quien fuera el padre de la patria chilena véase CHAUCA GARcía, Jorge: El irlandés Ambrosio O'Higgins: capitán general de Chile y virrey del Perú (1761-1801), Tesis Doctoral inédita defendida en la Universidad de Málaga en abril de 2014.

103. Millar Carvacho, René: «La Inquisición de Lima y la circulación de libros prohibidos (1700-1820)», Revista de Indias, Madrid, 1984, vol. XLIV, nº. 174, pp. 433-435.

104. A.H.N., Inquisición, leg. 2194, exp. 7. Cartagena de Indias, 24 de septiembre de 1807. Se aludía a diferentes cartas enviadas por el inquisidor general desde enero de 1805, ordenando reiteradamente hasta esa fecha de 1807 «quemar todos los libros obsenos y demás que existen en los archivos de este Supremo Consejo y tribunales provinciales del Santo Oficio». 
Un gran número de ejemplares fueron incluidos en los Index. En la coyuntura tratada, la actividad de prevención en cuanto a la posible contaminación de la población con las ideas que tan sutil y rápidamente podían correr en lugares estratégicos y alejados de la metrópoli, alcanzaba una importancia vital. Entre la formalización temporal de los índices debía acometerse la labor previa de hacer públicos edictos sobre obras concretas para el conocimiento de todos. Las listas, las meras menciones a obras o a la incipiente prensa que iniciaba la divulgación de cosas cotidianas, pero también de proclamas y principios defendidos en distintos puntos de Europa y de América del norte, debía tener una respuesta adecuada desde los instrumentos del poder desarrollados para ese fin. En cualquier tribunal inquisitorial de las colonias hispanas quedaba recogida la inquietud ante lo extendido a partir de la Revolución francesa y las ideas filosóficas circulantes en Europa: «que todos los dichos libros tratados y papeles, además de estar escritos con un estilo de puro naturalismo anticristiano, y maliciosamente oscuro y capcioso, manifiestan ser producciones de una nueva raza de filósofos, hombres de espíritu corrompido» ${ }^{105}$. El edicto inquisitorial en el que se inserta este párrafo recogía una relación de autores y obras de variada temática, pero de especial producción gala, al centrar en ese instante el mayor foco de inestabilidad político-social interna de una monarquía: Luvay, Lettre au Roi (1789), Cahiers general del plaintes..., o los periódicos Courrier patriotique, Le courrier de Versailles a Paris et de Paris a Versailles, Journal Ecclésiastique (1789), États-Generaux (Bayona, 1789); aunque también figuraban algunos títulos editados en Londres: Necker, De la importancia de la opinión (Londres, 1788). El espíritu de estas persecuciones, pese a estar lejos de los lugares de agitación y edición príncipe, estaba justificado pues era igual de «perjudicial leer libros de Grocio, Locke, Montesquieu, Beccaria o Filagieri en Cartagena de Indias que en Roma» ${ }^{106}$.

Se aludía en muchas ocasiones a la cuestión de las traducciones. En comunidades mayoritariamente analfabetas podría pensarse que el circular un volumen en idioma original, desconocido por la población salvo personas concretas, no tendría una gran repercusión o acogida, pero entraban en juego otros factores como la propia debilidad de una monarquía incapaz de garantizar el control de las ideas difundidas por las potencias enemigas. Máxime cuando, por regla general, los escritos atentaban directamente a la esencia de una forma de gobierno con evidentes fracturas internas. De esta forma, el original y la traducción debían ser retiradas de la circulación, y evitar «que de esta forma llegase a la mejor compresión general» ${ }^{107}$.

Así, el 17 de diciembre de 1803, se ordena prohibir la lectura y tenencia del libro Bororquia o la víctima de la Inquisición, impreso en Paris (1801), junto a otro de los

105. A.G.I., Indiferente, leg. 3014A. Edicto sobre prohibición de libros, fechado en México el 13 de marzo de 1790 .

106. A.G.I., Indiferente, leg. 3014B.

107. A.G.I., Indiferente, leg. 3014B. 
clásicos en los índices y edictos, el Contrato social de Rousseau, del cual existían varias traducciones al castellano, incluso para aquellas personas con licencia ${ }^{108}$.

El doctor don Bernardo de Prado y Ovejero, decano que fue del tribunal de la Inquisición en México, exponía el 18 de octubre de 1813, que «El molinismo, ha sido, a lo menos, tres veces extinguido y arrancadas las fetidas raizes que habían criado en muchos prosélitos de uno y otro sexo los secuaces de esta perversa secta», para continuar diciendo que «el atheismo fue también sofocado con la prisión y sentencia de los famosos don Antonio Olavarrieta ${ }^{109}$ y José Roxas, jamás se concluieron las causas en menos tiempo». Solicitaba licencia para volver a España tras más de 25 de años de servicio, 11 presidiendo el tribunal mexicano y 3 en Cartagena de Indias. Le fue restituido el pasaporte para él y sus familias ${ }^{110}$.

Restablecido el tribunal de Cartagena de Indias, una de las actuaciones relevantes en el punto que estamos tratando, del control de las ideas y su relación con la formación de un nuevo sistema político, serían los autos formados para prohibir un texto titulado Catecismo o ynstrucción popular ${ }^{111}$. Escrito por el «ciudadano» doctor Juan Fernández de Sotomayor, e impreso en la capital cartagenera, por Manuel González Pujol, fue incluido en el edicto correspondiente para evitar la difusión y lectura del mismo, siguiendo las pautas de lo realizado «del papel intitulado Los derechos del hombre, prohibido previamente en otro edicto de 27 de marzo de $1795^{112}$, pero en circulación en esos años debido al clima bélico e inestable experimentado en todo el territorio ${ }^{113}$. Volvían a restablecer las penas de excomunión por tal concepto, «aun a los licenciados de leer libros prohividos», y solicitaban al inquisidor general la aprobación de las medidas adoptadas. El motivo de la disposición era el carácter peligroso de ambos volúmenes al estimarse «papeles sediçiosos y subversivos, seductores, escandalosos e injuriosos a nuestro católico monarca y al Papa, y opuestos a las máximas de la Santa Religión, a cuya conservación, y la que pide la fidelidad al soberano ha obligado ha tomar esta oportuna determinación que aprueve el justificado zelo de esa superioridad». De nuevo, la utilización de la Inquisición como garante de la estabilidad social, y de la ineludible alianza o equilibrio de poderes de la monarquía y la Iglesia.

La estructura de la obra responde perfectamente a lo recogido en su definición por el Diccionario de la Lengua Española: «Obra que, redactada frecuentemente en preguntas y respuestas, contiene la exposición sucinta de alguna ciencia o arte». Pero

108. A.G.I., Indiferente, leg. 3014A.

109. A.G.I., Estado, leg. 30, nº 41. El virrey de Nueva España, don José de Yturrigaray, daba cuenta en mayo de 1804 del traslado del Olavarrieta, preso por el tribunal inquisitorial.

110. A.G.I., Indiferente, leg. 3014B.

111. A.H.N., Inquisición, leg. 2194, exp. 13.

112. Este libro, presente asiduo de los Index y edictos inquisitoriales sobre la materia, lo volvía a ser en esta ocasión, de 1815, pues su «objetivo es inspirar y favorecer la livertad de religión, turbando el buen orden y gobierno establesido por su majestad en estos dominios en qualquier idioma en que se hallare».

113. A.H.N., Inquisición, leg. 2193, exp. 11. 
además, el concepto de catecismo aplicado a la obra referenciada pretende adoctrinar pedagógicamente, pero salvando las directrices espirituales que pudieran recogerse en los catecismos tradicionales de la Iglesia católica. No obstante, el autor lejos de renegar de su función sacerdotal, recomienda la lectura al conjunto del clero parroquial, por corresponderle la «defensa de la Religión santa de que somos ministros, extirpar de una vez el herror que tanto la injuria y degrada, error que hace a una Religión de amor y caridad, cómplice en la crueldades y asesinatos de una conquista bárbara y feroz» ${ }^{114}$.

En cuanto al contenido la pequeña obra de quien fuera «cura rector y vicario juez eclesiástico de la valerosa villa de Mompox», y llegara en 1834 a la mitra de su ciudad natal, Cartagena de Indias, está considerado el precursor de una literatura justificadora y argumentadora de los principios independentistas en Hispanoamérica ${ }^{115}$. En el examen del texto, el gobernador y el inquisidor responsable de la jurisdicción aunaron esfuerzos en resolver la denuncia, comprometiéndose el tribunal del Santo Oficio, desde Santa Marta el 6 de junio de 1815, en tomar «las más prontas y activas providencias para recogerlo y de que no se propaguen producciones subversivas al Estado y a la Religión ${ }^{116}$. Al día siguiente se determina pasar a los calificadores con el objeto de establecer las censuras pertinentes, pues la obra recogía «unas expresiones tan erróneas, criminales y rebolucionarias mucho más fuertes que las que refiere el patriotismo de Nirgua y abuso de los Reyes ${ }^{117}$, que está prohivido». A las dos semanas es redactado el dictamen para prohibirlo y recoger los ejemplares del «libelo», por cuanto atentaba contra la nación española, y vertía opiniones en la línea de las que habían «corrompido a la Europa» y se habían extendido las revueltas a Latinoamérica. Concluyó el proceso con la publicación del edicto correspondiente, de la manera habitual: «en voz alta en la Santa Yglesia Catedral, después del evangelio de la misa mayor, el día de ayer, dos del corriente, y concluida se fixó en el parage acostumbrado» ${ }^{118}$.

La actividad de prohibición de obras continuaría después de 1814, una vez autorizada la apertura de los distritos inquisitoriales, y devolución del patrimonio incautado. Dicha labor la enfocarían hacia libros tradicionalmente proscritos y otros ejemplares de nuevo cuño. Entre las señaladas en el tribunal cartagenero tendríamos: los «papeles» de la recién creada «secta llamada Bíblica» y la obra Memorias sobre la revolución en España del abad francés Prat, publicada inicialmente en París y tradu-

114. A.H.N., Inquisición, leg. 1605, exp. 9.

115. Javier Ocampo López, El cura Juan Fernández de Sotomayor y Picón y los catecismos de la Independencia (Bogotá: Universidad del Rosario, 2010), 9-10.

116. A.H.N., Inquisición, leg. 2194, exp. 13.

117. Indudablemente se trata del texto de Juan Germán Roscio, Patriotismo de Nirgua y abuso de los Reyes, Palacio federal de Venezuela, 18 de septiembre de 1811.

118. A.H.N., Inquisición, leg. 1605, exp. 9. Santa Marta, 3 de julio de 1815. 
cida al español en Bayona ${ }^{119}$; el periódico titulado El Español Constitucional, cuyas censuras y calificaciones en el seno del Santo Oficio se producen en 1818 en la metrópoli ${ }^{120}$, y comienzan a tener más información en el tribunal de Cartagena de Indias al año siguiente ${ }^{121}$.

\section{CONCLUSIONES}

De una Inquisición un tanto languidecida o aletargada se pasa a adquirir un mayor protagonismo en el control de las ideas. La segunda mitad del siglo XVIII representa la época donde se llevará a cabo la expansión de los principios defendidos en la Ilustración en buena parte de los territorios bajo soberanía española, a la vez de las décadas en que comienza a gestarse las reformas estructurales de la sociedad y el planteamiento, y concreción en algunos casos, de cambios significativos en el orden político establecido. De esta manera, la secular alianza Altar-Trono debía fortalecerse, incluso con la renuncia de aquel a ciertas reivindicaciones sobre materias concretas perdidas desde finales del siglo XV. En este contexto el Santo Oficio, institución paraestatal paradigmática, recogía a la perfección la simbiosis de ambos, y contribuiría a ejercer más activamente el tan deseado control sobre personas e ideas.

Una institución que se resistía a perder por completo el poder e influencia ostentados durante siglos, y muchos de sus miembros seguían solicitando una reestructuración administrativa, en un contexto político en el que la Inquisición había manifestado el apoyo público a la causa regalista frente al enemigo francés.

Una actividad preventiva con el control de libros y persecución de proclamas ${ }^{122}$, pero también la represión de aquellos que no se hubieran caracterizado por defender los derechos e intereses de la Monarquía, la Religión y el Santo Oficio.

Todo lo expuesto es perfectamente constatado en el distrito inquisitorial cartagenero, reproduciendo los tradicionales conflictos con otras instituciones de la Monarquía, aunque adquiriendo allí una significación especial por el territorio en el cual se materializaba la acción de gobierno.

Además, el periodo contemplado en este trabajo supone un marco donde las controversias de índole cultural o «espiritual», siempre bajo la atenta mirada del Santo Oficio, adquirirán una mayor repercusión y trascendencia al situarse en el ámbito político, en un arco cronológico dominado por la inestabilidad de gobierno y la insurgencia de determinados grupos frente a la metrópoli. Durante esa etapa, el control sobre las ideas, mediante el tradicional instrumento de restringir la circulación de libros prohibi-

119. A.H.N., Inquisición, leg. 2194, exp. 10. Los «papeles» de la Bíblica, figuraban en cartas del 6 y 8 de octubre de 1816, por un escrito datado en Cartagena de Indias el 15 de abril de 1817. En cuanto a la obra del abad, el 13 de febrero de 1817 ratificaban la prohibición anterior de 12 de agosto de 1816 .

120. A.H.N., Inquisición, leg. 4464, exp. 1.

121. A.H.N., Inquisición, leg. 2194, exp. 11. En este caso señalan los inquisidores a un bibliotecario llamado Gallardo, que junto a otros refugiados en Londres pretendían "publicar ofensas al rey».

122. A.H.N., Inquisición, leg. 2194, exp. 7. 
dos, o la intervención de posibles «contaminaciones» del exterior, estuvieron siempre muy presentes, sin menospreciar la actividad ejercida sobre miembros concretos de las logias masónicas, quienes fueron procesados por el tribunal de la Inquisición, acusados de vinculaciones con el movimiento independentista. 